\title{
Effects of prenatal exposure to chronic caffeine on locomotor and emotional behavior
}

\author{
R. N. HUGHES and I. J. BEVERIDGE \\ University of Canterbury, Christchurch, New Zealand
}

\begin{abstract}
Following chronic prenatal exposure to 24 or $44 \mathrm{mg} / \mathrm{kg}$ per day caffeine added throughout gestation to the drinking water of pregnant rats, open-field behavior and latencies to emerge from a dark to a brightly lit area were observed in offspring at mean ages of 73, 117, and 171 days. The higher dose decreased locomotor activity at all ages and increased defecation for females and the number of male rats that failed to emerge in the emergence tests. Prenatal caffeine also increased relative adrenal weights in 90-day-old male subjects. It was concluded that prenatal exposure to $44 \mathrm{mg} / \mathrm{kg}$ per day caffeine led to increased emotional reactivity in the offspring and thus decreased locomotor activity.
\end{abstract}

As a consequence of reports of greater perinatal risk, developmental delays, and physical abnormalities in the offspring of rodents and humans following high daily caffeine intake during pregnancy (e.g., Fujii \& Nishimura, 1972; Gilbert \& Pistey, 1973; Nolan, 1981; Palm et al., 1978; Weathersbee, Olsen, \& Lodge, 1977), there has been increased interest in subsequent behavioral effects of pre- and perinatal exposure to lower levels of the drug. A frequent result has been increased motor activity in caffeine-exposed rat offspring up to about 2 months after birth, when observations have typically ceased (Hughes \& De'Ath, 1983; Peruzzi et al., 1983; Lombardelli, Balduini, Feduzi, Peruzzi, \& Cattabeni, 1984; Sobotka, Spaid, \& Brodie, 1979). Hughes and Beveridge (1986a) therefore investigated prenatal caffeine effects on rats observed 61,145 , or 188 days after birth, in a study designed to avoid the lack of fostering procedures and observations of both sexes beyond about 60 days of age that had characterized a number of earlier studies. Their pregnant dams had received 10 daily intraperitoneal injections of $10-40 \mathrm{mg} / \mathrm{kg}$ caffeine or control vehicle, and all offspring were observed in an open field. In general, prenatal caffeine increased locomotor activity at 61 days, had no effect at 145 days, and decreased the behavior at 188 days. Male offspring were more affected by the treatment than were females. Of particular interest was the prenatal caffeine-induced decrease in locomotor activity of 6-month-old rats, which has also been noted for nonspecific general activity in males only (Hughes \& Beveridge, 1986b). A similar result was reported by Concannon, Braughler, and Schechter (1983) for the effects of chronic pre- and perinatal caffeine in drinking water on general activity in cross-fostered rats of both sexes observed only up to 35 days after birth. More recently, Glavin and Krueger (1985) failed to demonstrate any effects of prenatal chronic caffeine on

Requests for reprints should be sent to R. N. Hughes, Department of Psychology, University of Canterbury, Christchurch 1, New Zealand. either open-field ambulation or defecation in fostered rats observed up to 196 days after birth.

Nevertheless, Hughes and Beveridge (1986a, 1986b) suggested that the behavioral effects of prenatal caffeine (in particular, activity decrements) may be due in part to increased emotional reactivity in the offspring. This suggestion is supported by changes in several other responses often adopted as emotionality indices: decreased passive avoidance latencies and increased occupancy of open-field corners, defecation, grooming, and latencies to enter a brightly lit or conditioned aversive environment by rats and mice prenatally exposed to caffeine (Butcher, Vorhees, \& Wootten, 1984; Hughes \& Beveridge, 1986a; Peruzzi et al., 1983; Sinton, Valatx, \& Jouvet, 1981). Glavin and Krueger (1985) also showed that prenatal caffeine increases susceptibility to stress-induced gastric ulcers.

Because pregnant dams in the studies of Hughes and Beveridge (1986a, 1986b) received caffeine via daily injections, and route of administration may influence prenatal caffeine effects (Concannon et al., 1983; Palm et al., 1978), the present study was designed to reassess the outcomes in fostered male and female offspring of dams that had ingested caffeine in their drinking water throughout pregnancy. In view of the sensitivity of activity profiles as indices of prenatal caffeine effects (Concannon et al., 1983) and uncertainty about underlying behavioral mechanisms, it was decided to apply open-field and emergence tests, rather than more rigorous procedures that could restrict response options available to the subjects.

\section{METHOD}

\section{Subjects}

A total of 68 female Wistar rats ( 180 days old) were selected for breeding. They were individually housed in $46 \times 29 \times 16.5 \mathrm{~cm}$ high plastic cages, each with a stainless steel mesh lid containing a food basket of standard laboratory diet and a $500-\mathrm{ml}$ glass bottle plus drinking tube. The floor was covered with regularly changed toxin-free sawdust. All dams were maintained on a 12-h reversed light-dark cycle in an ambient temperature of $21^{\circ}-23^{\circ} \mathrm{C}$. 
By daily microscopic examination for $\mathbf{3 0}$ days of the vaginal epithelium of 8 randomly selected individuals, it was possible to estimate periods of maximum fertility for the sample. Each dam was then paired with a male Wistar for $72 \mathrm{~h}$. Conception was assumed when spermatozoa were observed in two vaginal smears taken at $24-\mathrm{h}$ intervals. The males were then removed and the dams assigned to one of three treatment groups: control $(n=44)$, lowdose caffeine $(n=13)$, and high-dose caffeine $(n=11)$. Control dams were provided with tap water for drinking, whereas caffeinetreated subjects had access only to caffeine solutions. On the basis of prior measurements of water consumption, the solutions contained either $0.15 \mathrm{mg} / \mathrm{ml}$ or $0.3 \mathrm{mg} / \mathrm{ml}$ caffeine in order to provide daily caffeine intakes of about $20 \mathrm{mg} / \mathrm{kg}$ (low dose) or $40 \mathrm{mg} / \mathrm{kg}$ (high dose). From the day all males were removed until parturition, measurements were made every 2 or 3 days of maternal body weight and volume of fluid per day consumed. Within $15 \mathrm{~h}$ of birth, each control and caffeine-exposed litter was weighed and the pups were counted and then fostered to a control dam to ensure that no offspring were reared by caffeine-treated rats. When 30 days old, the pups were weaned and caged in groups of 4 or 5 of the same sex.

\section{Apparatus and Procedure}

About 18-20 days after mating, 8 pregnant dams (determined by body weight increases) from each group were individually observed for $5 \mathrm{~min}$ in a $60 \times 60 \times 30 \mathrm{~cm}$ high Perspex open field with transparent walls and a floor divided into 16 numbered squares. The field was illuminated by room fluorescent lighting that provided a floor light level of $23 \mathrm{~lx}$. Background sounds were masked by 58-dB white noise measured within the apparatus. Every $5 \mathrm{sec}$ an experimenter noted which square the rat was in and whether it was walking, rearing, or grooming. In addition to recording occupancy of corner and center squares, the location measure enabled later assessments of distance traveled (ambulation) by counting the number of times an occupied square differed from that occupied during the immediately preceding 5-sec observation. Fecal boli were also counted and removed. Following its open-field test, each rat's latency to emerge within $300 \mathrm{sec}$ from a $20 \times 15 \times 20 \mathrm{~cm}$ high darkened chamber into a brightly lit $50 \times 40 \times 20 \mathrm{~cm}$ high area with white walls was also recorded. Illumination was provided at a level of $60 \mathrm{Ix}$ by fluorescent tubes underneath the opaque Perspex floor of the arena. Auditory masking was via $54-\mathrm{dB}$ white noise (measured within the apparatus).

Open-field behavior and emergence latencies were recorded for 24 offspring ( 12 male, 12 female) from each prenatal treatment group at approximately 73 (mean $\pm S E=73.33 \pm .27), 117(117 \pm$ $.34)$, and 171 days (171.25 \pm .49$)$ after birth. The control, low-, and high-dose groups comprised individuals from 9,6 , and 8 litters, respectively. The apparatus and procedure at each testing age were the same as for the earlier behavioral tests of pregnant dams. All observations were single-blind. Another 890 -day-old rats (4 males, 4 females) from each prenatal exposure condition were sacrificed and their adrenal glands were removed, cleaned of all surrounding tissue, and weighed. Paired adrenal weights relative to body weight $(\mathrm{mg} / 100 \mathrm{~g})$ were determined for each individual.

\section{RESULTS}

\section{Maternal and Prefostering Observations}

Maternal caffeine dose, fluid intake, and body weight. From measurements of maternal fluid consumption and body weight of dams who subsequently littered, the mean $( \pm S E)$ daily caffeine intakes for the low- and high-dose subjects were calculated to be $23.80 \pm 2.32$ (24) and $43.69 \pm 2.26(44) \mathrm{mg} / \mathrm{kg}$, respectively.

Six 24-mg/kg dams and $844-\mathrm{mg} / \mathrm{kg}$ dams produced viable litters. Figure 1 shows changes in body weight and fluid intake during gestation for these and 8 randomly selected control dams that produced viable litters. According to a two-way ANOVA, there were no significant differences in body weight among the three groups $[F(2,19)<1]$. Increases during gestation were, of course, highly significant $[F(7,133)=165.97, p<.0001]$.

Fluid intake varied significantly during gestation $[F(7,133)=8.34, p<.001]$. Although the overall

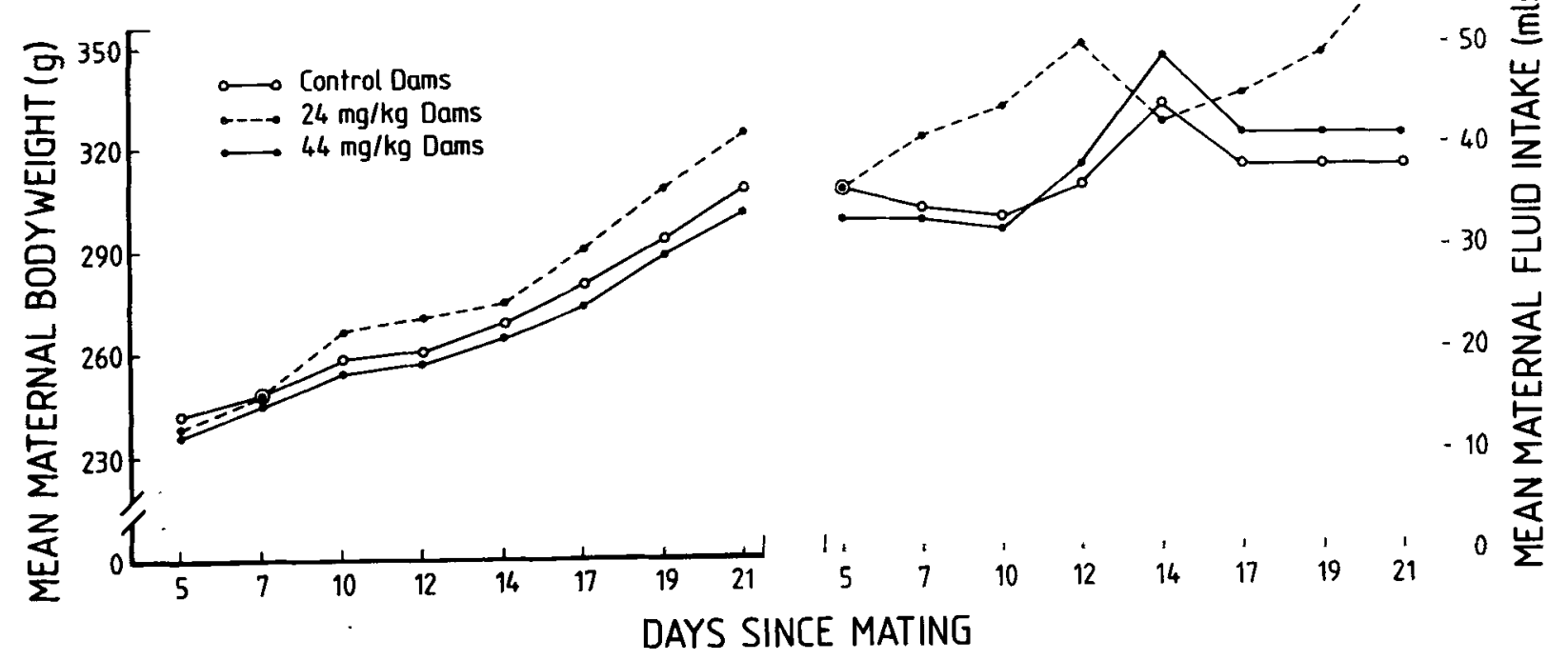

Figure 1. Changes in maternal body weight and fluid intake during gestation for pregnant dams that drank tap water (control) or solutions containing $24 \mathrm{mg} / \mathrm{kg}$ or $44 \mathrm{mg} / \mathrm{kg}$ caffeine. 
Table 1

Mean ( $\pm S E$ ) Open-Field and Emergence Test Scores in Pregnant Dams That Drank Tap Water (Control) or Solutions Containing 24 or $44 \mathrm{mg} / \mathrm{kg}$ Caffeine During Gestation, and Results of ANOVAs

\begin{tabular}{|c|c|c|c|c|c|c|c|}
\hline \multirow[b]{3}{*}{ Measure } & \multicolumn{6}{|c|}{ Caffeine Treatment } & \multirow[b]{3}{*}{$F(2,21)$} \\
\hline & \multicolumn{2}{|c|}{ Control } & \multicolumn{2}{|c|}{$24 \mathrm{mg} / \mathrm{kg}$} & \multicolumn{2}{|c|}{$44 \mathrm{mg} / \mathrm{kg}$} & \\
\hline & Mean & $S E$ & Mean & $S E$ & Mean & $S E$ & \\
\hline Walking & 7.00 & 1.32 & 8.5 & .96 & 11.25 & 1.50 & 2.83 \\
\hline Rearing & 5.63 & 2.26 & 7.63 & 1.02 & 6.50 & .88 & $<1$ \\
\hline Ambulation & 27.38 & 3.45 & 37.75 & $2.74^{*}$ & 42.50 & $2.54^{*}$ & $6.88 \dagger$ \\
\hline Corner Occupancy & 46.38 & 1.87 & 33.63 & $4.11^{*}$ & 36.13 & $2.30^{*}$ & $5.34 \ddagger$ \\
\hline Grooming & 2.38 & .56 & 2.5 & .63 & 1.5 & .42 & 1.00 \\
\hline Center Occupancy & 1.25 & .41 & 3.75 & 1.73 & 1.63 & .42 & 1.63 \\
\hline Fecal Boli Counts & 5.25 & .80 & 3.13 & 1.25 & 4.50 & .68 & 1.31 \\
\hline $\begin{array}{l}\text { Emergence Latency } \\
\text { (in seconds) }\end{array}$ & 83.25 & 47.33 & 64.75 & 37.10 & 49.63 & 35.85 & 2.05 \\
\hline
\end{tabular}

*Significantly different from control group ( $p<.05$, Dunnett's test). $\quad \nmid p<.01 . \quad \ddagger p<.025$.

prenatal treatment effect was not significant $[F(2,19)=$ $2.47, p>.05]$, a significant interaction occurred between treatment and days since mating $[F(14,133)=2.63$, $p<.01]$. Inspection of Figure 1 reveals a sudden increase in fluid intake 12 days after mating for $24-\mathrm{mg} / \mathrm{kg}$ dams and similar increases at 14 days for the other two groups. According to Dunnett's tests $(p<.05)$, the increase between Days 5 and 12 but not between Days 5 and 21 was significant for control dams. Increases were significant for $24-\mathrm{mg} / \mathrm{kg}$ dams between Day 5 and Days $12,17,19$, and 21 , and for $44-\mathrm{mg} / \mathrm{kg}$ dams between Day 5 and Days 14, 17, 19, and 21. In other words, unlike control dams, both caffeine-treated groups increased their fluid intake between the beginning and end of the postmating period. Rats in the $24-\mathrm{mg} / \mathrm{kg}$ group also consumed significantly more fluid on Day 21 than did their 44-mg/kg counterparts.

Maternal behavior. Effects of the maternal caffeine treatment on open-field behavior and emergence latencies and results of ANOVAs can be seen in Table 1. Both doses of chronic caffeine significantly increased ambulation and decreased corner occupancy. These two measures were significantly negatively correlated with each other [Pearson $r(22)=.79, p<.01]$. No other measure was affected by caffeine.

Litter size and weight. Of those originally mated, only 23 control (52.28\%), $624-\mathrm{mg} / \mathrm{kg}(46.15 \%)$, and $844-$ $\mathrm{mg} / \mathrm{kg}(72.73 \%)$ dams produced litters. However, differences between these numbers were not significant $\left[\chi^{2}(2)\right.$ $=1.92, p>.3]$. According to body-weight changes, 2 other $24-\mathrm{mg} / \mathrm{kg}$ dams must have littered but eaten their young before the births were noted. One $44-\mathrm{mg} / \mathrm{kg}$ litter died soon after fostering. Thirteen control (5.91\%), $124-$ $\mathrm{mg} / \mathrm{kg}(1.59 \%)$, and $344-\mathrm{mg} / \mathrm{kg}(4.92 \%)$ pups were born dead or died soon after birth and prior to fostering. These numbers were not significantly different $\left[\chi^{2}(2)=1.90\right.$, $p>.3]$.

Litter sizes, birth weights, and results of ANOVAs can be seen in Table 2. Neither of these measures was significantly affected by prenatal caffeine exposure, nor were there any examples of obvious physical abnormalities.

\section{Postfostering Observations of Offspring}

Relative adrenal weights. Because changes in relative adrenal weight can differ between males and females (Hatch, Wiberg, Balazs, \& Grice, 1963; Hatch et al., 1965; Hughes \& Syme, 1972), and because the data were not normally distributed, Mann-Whitney $U$ tests were performed between control and pooled caffeine-exposed subjects for each sex separately. The difference was significant for males (control median $=9.56 \mathrm{mg} / 100 \mathrm{~g}, n=4$; caffeine-exposed median $=17.07 \mathrm{mg} / 100 \mathrm{~g}, n=8 ; U$ $=3, p=.028$ ) but not for females (control median $=$ $24.85 \mathrm{mg} / 100 \mathrm{~g}, n=4$; caffeine-exposed median = $25.41 \mathrm{mg} / 100 \mathrm{~g}, n=8 ; U=10, p>.3$ ), whose relative adrenal weights were significantly higher (median = $24.8 \mathrm{mg} / 100 \mathrm{~g}, n=12$ ) than those of males (median $=$ $13.50 \mathrm{mg} / 100 \mathrm{~g}, n=12 ; U=18, p<.002$ ).

Open-field behavior. Differences between the effects of prenatal caffeine exposure on all open-field measures,

Table 2

Mean ( $\pm S E$ ) Number of Pups and Average Birth Weight per Litter Delivered by Female Rats That Drank Tap Water (Control) or Solutions Containing $24 \mathrm{mg} / \mathrm{kg}$ or $44 \mathrm{mg} / \mathrm{kg}$ Caffeine During Gestation, and Results of ANOVAs

\begin{tabular}{|c|c|c|c|c|c|c|c|}
\hline \multirow[b]{3}{*}{ Measure } & \multicolumn{6}{|c|}{ Prenatal Caffeine Treatment } & \multirow[b]{3}{*}{$F(2,34)$} \\
\hline & \multicolumn{2}{|c|}{ Control } & \multicolumn{2}{|c|}{$24 \mathrm{mg} / \mathrm{kg}$} & \multicolumn{2}{|c|}{$44 \mathrm{mg} / \mathrm{kg}$} & \\
\hline & Mean & $S E$ & Mean & $S E$ & Mean & $S E$ & \\
\hline $\begin{array}{l}\text { Number of Pups } \\
\text { per Litter }\end{array}$ & 9.09 & .67 & 12.00 & 1.13 & 7.86 & 1.32 & 2.88 \\
\hline $\begin{array}{l}\text { Average Birth Weight } \\
\text { per Litter (g) }\end{array}$ & 5.54 & .12 & 5.40 & .16 & 5.35 & .25 & $<1$ \\
\hline
\end{tabular}


except fecal boli counts, at the three testing ages can be seen in Figure 2. Separate three-way ANOVAs (prenatal caffeine $\times$ sex $\times$ testing age) were performed on data outlined in the figure. Because of very high within-litter variability, it seemed unlikely that the responses of littermates were correlated. In view of similar levels of within- and between-litter variability, individual littermate scores were treated as independent in the present and later analyses. The ANOVAs revealed significant prenatal caffeine effects for walking $[F(2,66)=6.23, p<.01]$, ambulation $[F(2,66)=6.88, p<.01]$, and corner occupancy $[F(2,66)=3.82, p<.05]$. According to Dunnett's tests $(p<.05)$, differences between the control and the $44-\mathrm{mg} / \mathrm{kg}$ but not the $24-\mathrm{mg} / \mathrm{kg}$ group were significant for each of these measures.

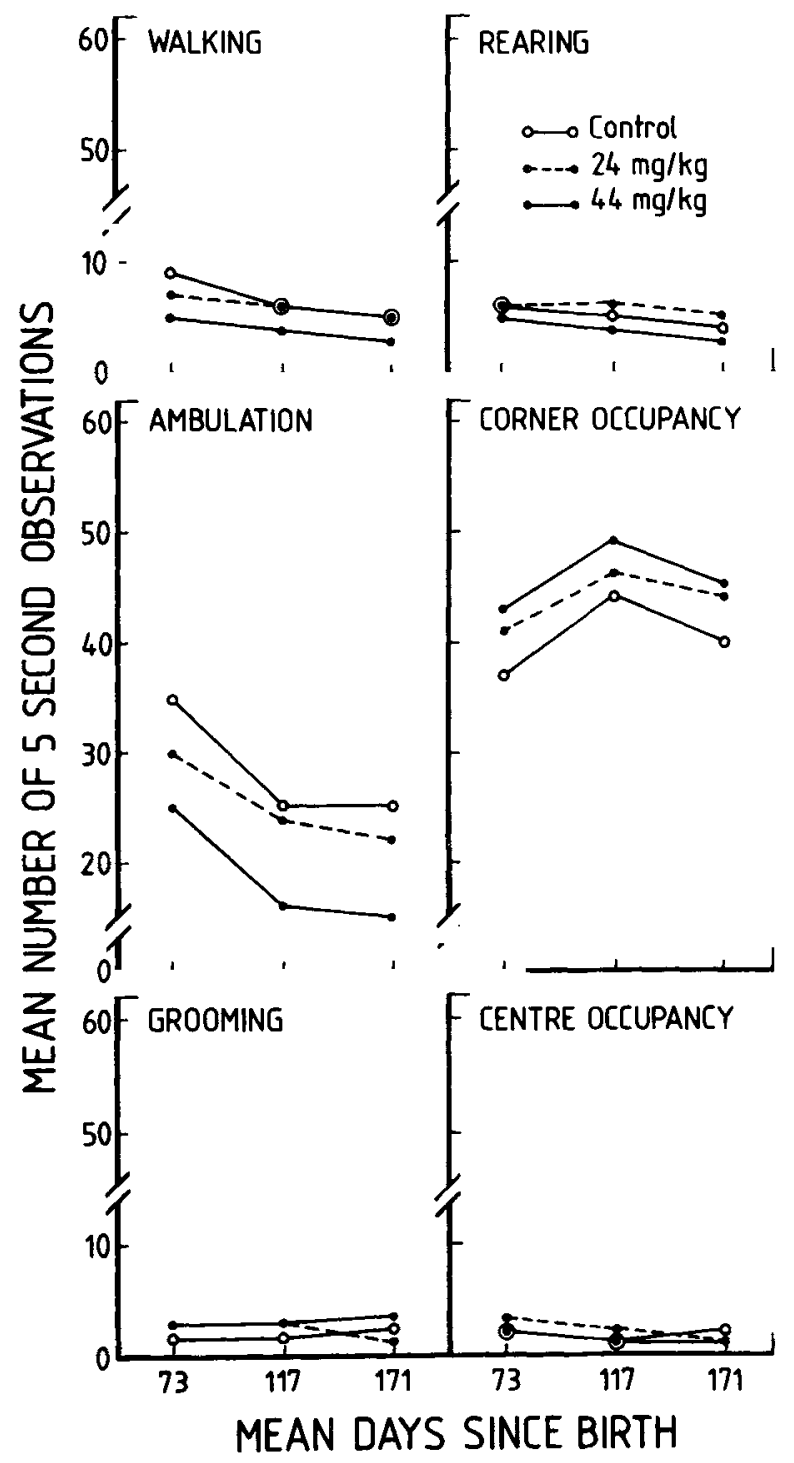

Figure 2. Frequencies of six open-field measures observed at three testing ages for the offspring of female rats that drank tap water (control) or solutions containing $24 \mathrm{mg} / \mathrm{kg}$ or $44 \mathrm{mg} / \mathrm{kg}$ caffeine during gestation.
Except for grooming, testing age significantly affected the responses outlined in Figure $2[F \mathrm{~s}(2,132)=$ $4.01-21.19, p \mathrm{~s}<.025-.001]$. There was a significant decrement $(p<.05)$ between 73 and 171 days in each case except for corner occupancy. The rats occupied significantly more corner squares when they were 117 days old than when they were 71 or 171 days old. Only one sex difference was significant, namely that for rearing [male mean $\pm S E=3.71 \pm .52$, female mean $=6.06$ $\pm .89 ; F(1,66)=9.83, p<.01]$. No two- or three-way interactions were significant.

Because a sizable proportion of subjects failed to defecate in one or more of these tests, prenatal caffeine effects on fecal boli counts were nonparametrically analyzed for each sex separately. Median boli counted during all three tests for the control, $24-\mathrm{mg} / \mathrm{kg}$, and $44-\mathrm{mg} / \mathrm{kg}$ groups were $10.5,9.5$, and 12.0 , respectively, for males and 8.0, 10.0, and 10.5 for females. Extended median tests revealed a significant effect for females $\left[\chi^{2}(2)=\right.$ $6.24, p<.02]$ but not for males $\left[\chi^{2}(2)<1\right]$. The only significant difference for females was between the control and $44-\mathrm{mg} / \mathrm{kg}$ groups $(p<.05$ ). Overall, males (median $=11.0$ ) defecated more often than females [median $=9.0 ;$ median test $\left.\chi^{2}(1)=5.56, p<.02\right]$. Median boli counts for the combined sexes at 71,117 , and 171 days of age were $1.5,4.0$, and 5.0, respectively. According to a Friedman test, differences between boli at these ages were significant $\left[\chi^{2}(2)=22.17, p<.001\right]$. Subsequent sign tests revealed a significant increase $(p<.05)$ between 71 and 117 days and between 71 and 171 days.

Emergence latencies. In each emergence test, a considerable number of subjects did not emerge within the 300 -sec upper limit. Prenatal caffeine effects were therefore determined by chi-square tests performed on numbers of each sex that failed to emerge on more than one of their three tests. For the control, $24-\mathrm{mg} / \mathrm{kg}$, and 44$\mathrm{mg} / \mathrm{kg}$ groups, respectively, $41.67 \%, 41.67 \%$, and $91.67 \%$ of males and $66.67 \%, 33.33 \%$, and $41.67 \%$ of females failed to emerge on more than one of the three tests. Differences between the groups were significant for males $\left[\chi^{2}(2)=8.29, p<.02\right]$ but not for females $\left[\chi^{2}(2)\right.$ $=2.90, p>.2]$. Significantly more $44-\mathrm{mg} / \mathrm{kg}$ $(p<.05)$, but not $24-\mathrm{mg} / \mathrm{kg}$, males failed to emerge than did controls. Although the overall difference between numbers of males $(58.33 \%)$ and females $(47.22 \%)$ that failed to emerge was not significant $\left[\chi^{2}(1)<1\right]$, a Cochran $Q$ test showed that the numbers of nonemergers of both sexes differed significantly at each testing age [71 days $=37.50 \% ; 117$ days $=54.17 \% ; 171$ days $=$ $58.33 \% ; Q(2)=7.56, p<.05$ ]. There was a significant increase $(p<.05)$ only between Days 71 and 171 .

Relationships between locomotor, location, and emotionality measures. Fecal boli counts and latencies of emergence from a sheltered area are widely accepted as indices of emotionality in rats (Archer, 1973). In view of the already described changes in these measures, it was desirable to determine their relationships with those locomotor and location measures affected by prenatal caffeine, 
Table 3

Percentages of Rats Above and Below Median Walking, Ambulation, and Corner Occupancy Scores That Defecated More Than Once or Failed to Emerge at All Three Testing Ages, and Results of Chi-Square Tests

\begin{tabular}{|c|c|c|c|c|}
\hline & Defecation & $\chi^{2}(1)$ & Failure to Emerge & $\overline{\chi^{2}(1)}$ \\
\hline \multicolumn{5}{|c|}{ Walking } \\
\hline $\begin{array}{l}\text { Above Median }(n=36) \\
\text { Below Median }(n=36)\end{array}$ & $\begin{array}{l}23.53 \\
50.00\end{array}$ & $4.29 *$ & $\begin{array}{c}0 \\
28.95\end{array}$ & $9.49 \dagger$ \\
\hline \multicolumn{5}{|c|}{ Ambulation } \\
\hline $\begin{array}{l}\text { Above Median }(n=34) \\
\text { Below Median }(n=38)\end{array}$ & $\begin{array}{l}16.67 \\
55.56\end{array}$ & $10.17 \dagger$ & $\begin{array}{r}2.78 \\
27.78\end{array}$ & $6.87 \dagger$ \\
\hline \multicolumn{5}{|c|}{ Corner Occupancy } \\
\hline $\begin{array}{l}\text { Above Median }(n=35) \\
\text { Below Median }(n=37)\end{array}$ & $\begin{array}{l}40.00 \\
32.43\end{array}$ & $<1$ & $\begin{array}{r}22.86 \\
8.11\end{array}$ & 1.99 \\
\hline
\end{tabular}

namely walking, ambulation, and corner occupancy (the latter measure has also been defined as an emotionality index [Morrison \& Thatcher, 1969]). Walking and ambulation scores for all three tests were positively correlated with each other $[r(70)=.82, p<.01]$, whereas both were negatively correlated with corner occupancy [walking-corner occupancy $r(70)=.63, p<.01$; ambulation-corner occupancy $r(70)=-.75, p<.01$ ]. Because of frequent boli counts of 0 and failures to emerge within $300 \mathrm{sec}$, total walking, ambulation, and corner occupancy scores were split at their respective medians into numbers of individuals above and below each median that, during all three tests, defecated more than once and failed to emerge. These numbers were then compared by means of chi-square tests (see Table 3). It was shown that rats with lower walking and ambulation scores were more likely to defecate and to fail to emerge, and vice versa. No relationship was evident between corner occupancy and the two emotionality measures.

\section{DISCUSSION}

Although increases in maternal body weight during gestation did not differ between the prenatal treatment conditions, caffeine-treated dams consumed more fluid (and thus more caffeine) near the end of pregnancy. This could have been due to increasing water loss arising from caffeine's diuretic action (Rall, 1980), moderated to some extent by possible taste aversions to the $44-\mathrm{mg} / \mathrm{kg}$ solution. However, diuresis alone is unlikely to account for subsequent offspring behavior, because similar behavioral effects occurred for 6-month-old offspring of pregnant dams given daily intraperitoneal caffeine injections while allowed ad-lib tap water (Hughes \& Beveridge, 1986a, 1986b). The inexplicable increases in fluid intake 12 and 14 days after mating may have arisen from some undetected change in ambient temperature or humidity occurring outside of times when measurements were made.

Although both caffeine doses increased open-field ambulation and the negatively correlated corner occupancy response in pregnant dams, they had no effect on other measures. (It later became apparent that low corner oc- cupancy merely reflected high locomotor activity, and vice versa.) Nevertheless, it was confirmed that the caffeine levels were sufficient to be behaviorally effective even though not anxiogenic. In line with previous findings (Concannon et al., 1983; Hughes \& Beveridge, 1986a; Lombardelli et al., 1984; Sobotka et al., 1979), perinatal mortality (but see Glavin \& Krueger, 1985), birth weight, and litter size were unaffected by prenatal caffeine exposure.

Maternal caffeine ingestion had several subsequent effects on the offspring. The most striking behavioral outcome was a decrease in walking frequency and ambulation (or distance traveled) with $44 \mathrm{mg} / \mathrm{kg}$ per day, which persisted for the entire duration of the study in spite of decrements in these responses with age. These results contrasted with those of a related study (involving daily intraperitoneal treatment of dams; Hughes \& Beveridge, 1986a) in which caffeine-induced decreases in locomotor activity were not evident until 6 months after birth. Route of administration therefore appears to influence prenatal caffeine effects, presumably through variations in the concentration of maternal plasma caffeine, which will determine the extent of fetal exposure to the drug. This in turn could determine which central mechanisms are affected and consequently how postnatal behavior develops. Therefore, in future research of this nature it may be useful to determine maternal and possibly fetal serum caffeine levels at various stages of gestation to ultimately enable more meaningful comparisons between different rodent studies and between rodent and human findings. Even though observations of littermates were judged sufficiently uncorrelated to be treated as independent, it would nevertheless be desirable also to ensure that animals from the same litter not appear in the same experimental group.

Concannon et al. (1983) reported that chronic caffeine in pregnant Sprague-Dawley rats reduced offspring general activity for 35 days after birth, when their observations ceased. The present results show that this effect lasts much longer, possibly indefinitely, and cannot therefore be ascribed to caffeine withdrawal. Although in the present experiment $24 \mathrm{mg} / \mathrm{kg}$ per day maternal caffeine did not significantly affect any measure, Concannon et al. 
(1983) found $14 \mathrm{mg} / \mathrm{kg}$ per day to be effective. This discrepancy could be due to differences between the two studies in testing age or rat strain. However, of greater concern is Glavin and Krueger's (1985) report of no effect of prenatal caffeine on open-field ambulation or defecation in fostered rats observed at 48,68 , and 196 days after birth. It is possible that their use of a lower maximum level of maternal caffeine ( $35 \mathrm{mg} / \mathrm{kg}$ per day) than the effective dose in the present study could account for the discrepant findings. Alternatively, their failure to consider an effect of days in analyses of data from four consecutive 2-min daily open-field tests at each age may have obscured any immediately apparent prenatal caffeine effects on initial tests. The lack of often-reported prenatal caffeine-induced increases in activity (e.g., Hughes \& De'Ath, 1983; Sobotka et al., 1979) in the present study is ascribed to its combination of chronic oral caffeine treatment of dams throughout pregnancy; fostering of all young, thereby preventing postnatal caffeine exposure; and testing of the same animals of both sexes at three different ages.

Sex-related effects of prenatal caffeine on open-field and general activity, reported earlier (Hughes \& Beveridge, 1986a, 1986b), were not evident in the present study. However, the increased fecal boli counts in females following exposure to $44 \mathrm{mg} / \mathrm{kg}$ per day caffeine may have been related to attainment of a ceiling level for control males. The greater number of $44-\mathrm{mg} / \mathrm{kg}$ males that failed to emerge in the emergence test was consistent with a sexrelated effect on emergence latency found earlier (Hughes \& Beveridge, 1986a). Higher relative adrenal weights for caffeine-exposed male rats may also have reflected a ceiling effect for females, whose overall relative weights were much higher than those of males. The inverse relationship between defecation and failure to emerge and the two locomotor measures supports the suggestion that frequency of the latter measures was determined by emotionality levels. The lack of a similar relationship for corner occupancy means that this response merely reflected activity levels, and is therefore of no value as an emotionality measure in the present experimental context.

In accord with the present findings, Henry and Stephens (1980) reported that 3 months' consumption of a 90 $\mathrm{mg} / \mathrm{kg}$ caffeine-in-coffee solution increased adrenal weights in male mice. In view of the small number of subjects involved, the fact that adrenal weights of rats were determined only at 90 days of age, the absence of any effect for females, and the lack of information on adrenal function, the adrenal weight results in the present study are of little interest by themselves. But seen as part of a more general picture that includes the behavioral results of the present study and caffeine's anxiogenic effects on human clinical and experimental subjects (Greden, 1974; Greden, Fontaine, Lubetsky, \& Chamberlin, 1978; Veleber \& Templer, 1984), increased adrenal weights are of more significance as a measure of responsiveness to stress (Hatch et al., 1963; Hughes \& Syme, 1972). The adrenal weight data are therefore consistent with increases in stress-related susceptibility to gastric ulceration (Glavin \& Krueger, 1985), and, along with the behavioral measures, suggest that prenatal caffeine may enhance a predisposition or "trait" to respond in a more emotional manner to mildly stressful environmental stimuli. This possibility is supported by prenatal caffeine-induced changes in several other behavioral indices of emotionality described in the introduction to this paper. Because locomotion and emotionality may be related in a U-shaped fashion (Lester, 1968), some earlier reported increases in activity following prenatal caffeine exposure may also have arisen from heightened emotional reactivity, particularly since they sometimes occurred at the same time as increased defecation and latencies to enter a conditioned aversive environment and decreased passive avoidance latencies (Butcher et al., 1984; Peruzzi et al., 1983; Sinton et al., 1981). The decrease in locomotor activity with age (also reported by some earlier authors; e.g., Goodrick, 1965, 1966; Thompson \& Lippman, 1975), accompanied by increased defecation and failure to emerge, suggests that, independently of prenatal caffeine effects, all rats became more emotional as they grew older.

It is not yet known how brain development is modified by prenatal caffeine to produce the postnatal behavioral effects described. Interference with mechanisms operated by neither noradrenaline nor dopamine seems to be responsible (Concannon et al., 1983; Sobotka et al., 1979). Because chronic prenatal, lactational, and postweaning caffeine treatment increases adenosine receptors in rats and mice (Abbracchio et al., 1984; Fredholm, 1982; Marangos, Boulenger, \& Patel, 1984), and because the drug's anxiogenic effects may involve antagonism of possibly anxiolytic adenosine activity (Marangos \& Boulenger, 1985), it is tempting to implicate adenosine in prenatal caffeine-induced increases in emotional reactivity. Increased adenosinergic depressive influences could explain the locomotor decrements observed in the present study. However, such an interpretation would predict reduced emotionality, rather than the heightened emotionality that characterized caffeine-exposed animals, because of increased adenosinergic anxiolytic activity. Nevertheless, future research should give due consideration to the possible role of adenosine in the behavioral effects of prenatal caffeine.

\section{REFERENCES}

Abbracchio, M. P., Balduini, W., Cimino, M., Lombardelli, G., Peruzzi, G., \& Cattabeni, F. (1984). Chronic caffeine treatment and adenosine receptors. Clinical Neuropharmacology, 7, 422-423.

ARCHER, J. (1973). Tests for emotionality in rats and mice: A review. Animal Behaviour, 21, 205-235.

Butcher, R. E., Vorhees, C. V., \& Wootten, V. (1984). Behavioral and physical development of rats chronically exposed to caffeinated fluids. Fundamental \& Applied Toxicology, 4, 1-13.

Concannon, J. T., Braughler, J. M., Schechter, M. D. (1983). Pre- and postmatal effects of caffeine on brain biogenic amines, cyclic nucleotides and behavior in developing rats. Journal of Pharmacology \& Experimental Therapeutics, 226, 673-679.

FREDHOLM, B. B. (1982). Adenosine actions and adenosine receptors 
after 1 week treatment with caffeine. Acta Physiologica Scandinavica, 115, 283-286.

Fuji, T., \& Nishimura, H. (1972). Adverse effects of prolonged administration of caffeine on rat fetus. Toxicology \& Applied Pharmacology, 22, 449-457.

GiLBerT, E. F., \& Pistey, W. R. (1973). Effect on the offspring of repeated caffeine administration to pregnant rats. Journal of Reproduction \& Fertility, 34, 495-499.

Glavin, G. B., \& Krueger, H. (1985). Effects of prenatal caffeine administration on offspring mortality, open-field behavior and adult gastric ulcer susceptibility. Neurobehavioral Toxicology \& Teratology, 7, 29-32.

GooDRICK, C. L. (1965). Social interactions and exploration of young, mature, and senescent male albino rats. Journal of Gerontology, 20, 215-218.

Goodrick, C. L. (1966). Activity and exploration as a function of age and deprivation. Joumal of Genetic Psychology, 108, 239-252.

Greden, J. F. (1974). Anxiety or caffeinism: A diagnostic dilemma. American Journal of Psychiatry, 131, 1089-1092.

Greden, J. F., Fontaine, P., Lubetsky, M., \& Chamberlin, K. (1978). Anxiety and depression associated with caffeinism among psychiatric patients. American Journal of Psychiatry, 135, 963-966.

Hatch, A. M., Wiberg, G. S., Balazs, T., \& Grice, H. C. (1963). Long-term isolation stress in rats. Science, 142, 507.

Hatch, A. M., Wiberg, G. S., Zawidzka, Z., CanN, M., Airth, J. M., \& GRICE, H. C. (1965). Isolation syndrome in the rat. Toxicology \& Applied Pharmacology, 7, 737-745.

Henry, J. P., \& Stephens, P. M. (1980). Caffeine as an intensifier of stress-induced hormonal and pathophysiologic changes in mice. Pharmacology, Biochemistry \& Behavior, 13, 719-727.

HugHES, R. N., \& BEVERIDGE, I. J. (1986a). Behavioral effects of prenatal exposure to caffeine in rats. Life Sciences, 38, 861-868.

Hughes, R. N., \& Beveridge, I. J. (1986b). Depressed activity in male but not female rats six months after prenatal exposure to caffeine. IRCS Medical Science, 14, 319.

Hughes, R. N., \& DE'ATh, C. P. (1983). Effect of prenatal caffeine on behaviour of young rats. IRCS Medical Science, 11, 504-505.

Hughes, R. N., \& SYme, L. A. (1972). The role of social isolation and sex in determining effects of chlordiazepoxide and methylphenidate on exploratory behaviour. Psychopharmacologia, 27, 359-366.

LESTER, D. (1968). Two tests of a fear-motivated theory of motivation. Psychonomic Science, 10, 385-386.

Lombardelli, G., Balduini, W., Feduzi, G., Peruzzi, G., \& CatTABENI, F. (1984). Long-lasting tolerance to stimulatory effects of perinatal caffeine treatment. Psychopharmacology, 84, 285-286.
Marangos, P. J., \& Boulenger, J. P. (1985). Basic and clinical aspects of adenosinergic neuromodulation. Neuroscience \& Biobehavioral Reviews, 9, 421-430.

Marangos, P. J., Boulenger, J. P., \& Patel, J. (1984). Effects of chronic caffeine on brain adenosine receptors: Anatomical and ontogenetic studies. Life Sciences, 34, 899-907.

MorRison, B. J., \& THATChER, K. (1969). Overpopulation effects on social reduction of emotionality in the albino rat. Journal of Comparative \& Physiological Psychology, 69, 658-662.

NolaN, G. A. (1981). The effect of brewed and instant coffee on reproduction and teratogenesis in the rat. Toxicology \& Applied Pharmacology, 58, 171-183.

Palm, P. E., Arnold, E. P., Rachwall, P. C., Leyczek, J. C., Teague, K. W., \& Kensler, C. J. (1978). Evaluation of the teratogenic potential of fresh-brewed coffee and caffeine in the rat. Toxicology \& Applied Pharmacology, 44, 1-16.

Peruzzi, G., Abbrachio, M. P., Cagiano, R., Coen, E., Cuomo, V., Galli, C. L., Lombardelli, G., Marinovich, M., \& CatTABENI, F. (1983). Enduring behavioral and biochemical effects of perinatal treatment with caffeine and chlordiazepoxide. In G. Zbinden, V. Cuomo, G. Racagni, \& B. Weiss (Eds.), Application of behavioral pharmacology in toxicology (pp. 217-236). New York: Raven Press.

RALL, T. W. (1980). Central nervous system stimulants: The xanthines. In A. G. Gilman, L. S. Goodman, \& A. Gilman (Eds.), The pharmacological basis of therapeutics (pp. 592-607). New York: Macmillan.

Sinton, C. M., ValatX, J. L., \& Jouvet, M. (1981). Gestational caffeine modifies offspring behaviour in mice. Psychopharmacology, $75,69-74$.

SobotKa, T. J., SPAID, S. L., \& Brodie, R. E. (1979). Neurobehavioral teratology of caffeine exposure in rats. Neurotoxicology, 1, 403-416.

Thompson, R. W., Lippman, L. G. (1975). The effect of age and postweaning and adult handling habituation on activity and exploration in the rat. Bulletin of the Psychonomic Society, 5, 285-288.

Veleber, D. M., \& TeMPLER, D. I. (1984). Effects of caffeine on anxiety and depression. Journal of Abnormal \& Social Psychology, 93, 120-122.

Weathersbee, P. S., Olsen, L. F., \& Lodge, J. R. (1977). Caffeine and pregnancy: A retrospective survey. Postgraduate Medicine, 62, 64-69.

(Manuscript received October 6, 1986; revision accepted for publication February 26, 1987.) 